\section{Case Reports in Gastroenterology}

Case Rep Gastroenterol 2017;11:686-693

DOI: $10.1159 / 000481938$

Published onlIne: November 10, 2017
(C) 2017 The Author(s)

Published by S. Karger AG, Basel

www.karger.com/crg

This article is licensed under the Creative Commons Attribution-NonCommercial 4.0 International License (CC BY-NC) (http://www.karger.com/Services/OpenAccessLicense). Usage and distribution for commercial purposes requires written permission.

\title{
Multifocal Mass Lesions in Autoimmune Pancreatitis
}

\author{
Kazuhiro Suzumura ${ }^{a}$ Etsuro Hatano ${ }^{a}$ Naoki Uyama ${ }^{a}$ Toshihiro Okada ${ }^{a}$ \\ Yasukane Asano $^{\mathrm{a}}{\text { Seikan } \mathrm{Hai}^{\mathrm{a}} \text { Keiji Nakasho }}^{\mathrm{b}}$ Jiro Fujimoto ${ }^{\mathrm{a}}$ \\ aDepartment of Surgery, Hyogo College of Medicine, Nishinomiya, Japan; ${ }^{b}$ Department of \\ Pathology, Hyogo College of Medicine, Nishinomiya, Japan
}

\section{Keywords}

Autoimmune pancreatitis · Multifocal mass lesions · lgG4 · Pancreatic cancer · Total pancreatectomy
Abstract comments.

A 59-year-old male patient with jaundice was referred to our hospital because of mass lesions in the pancreatic head and tail. An immunological examination revealed an elevated serum IgG4 level. Computed tomography showed two clear boundary mass lesions in the pancreatic head and tail. Magnetic resonance imaging showed that the mass lesions exhibited low intensity on T1weighted images and iso-intensity on T2-weighted images. Magnetic resonance cholangiopancreatography showed an obstruction of the main pancreatic duct in the pancreatic head and tail. The possibility of malignant tumors could not be ruled out; therefore, we performed total pancreatectomy. A histopathological examination of the nodular lesions revealed severe lymphoplasmacytic infiltration and inflammatory change around the pancreatic ducts. Immunohistochemistry revealed diffuse infiltration of IgG4-positive plasma cells in the nodules. According to these pathological findings, we diagnosed the patient with IgG4-related multifocal mass lesions of autoimmune pancreatitis (AIP). It is difficult to distinguish between focal type AIP and pancreatic cancer. We herein report a rare case of multifocal mass lesions in AIP and include bibliographical 


\section{Case Reports in \\ Gastroenterology}

Case Rep Gastroenterol 2017;11:686-693

(c) 2017 The Author(s). Published by S. Karger AG, Base www.karger.com/crg

Suzumura et al: Multifocal Mass Lesions in Autoimmune Pancreatitis

\section{Background}

Autoimmune pancreatitis (AIP) is an uncommon form of chronic pancreatitis associated with an autoimmune inflammatory process [1]. Although diffuse swelling of the pancreatic parenchyma and diffuse irregular narrowing of the pancreatic duct system are morphologically characteristic of AIP, a focal type has recently been recognized [2-4]. The focal type AIP exhibits a localized mass lesion in the pancreas, similar to pancreatic cancer (PC), and often exhibits obstructive jaundice, which is also characteristic of PC, when the lesion involves the head of the pancreas [5]. Because AIP responds well to steroid therapy, it is very important to distinguish between AIP and PC.

There have only been a few cases of AIP with multifocal mass lesions [6-12]. We herein report a rare case of multifocal mass lesions in AIP and include pertinent bibliographical comments.

\section{Case Presentation}

A 59-year-old male patient was seen at another hospital because of jaundice. Computed tomography (CT) revealed intrahepatic bile duct dilatation and two pancreatic mass lesions in the pancreatic head and tail. He underwent endoscopic retrograde cholangiopancreatography and received an endoscopic nasobiliary drainage tube in the common bile duct. He was referred to our hospital for a close inspection and treatment purposes upon being indicated as having pancreatic mass lesions by a local doctor in 2010 . He had no medical history of autoimmune disease or excessive alcohol intake. On laboratory examination, the serum levels of total bilirubin, alkaline phosphatase and $\gamma$-glutamyl transpeptidase were elevated to $5.0 \mathrm{mg} / \mathrm{dL}$ (normal range $0.2-1.2 \mathrm{mg} / \mathrm{dL}$ ), $391 \mathrm{U} / \mathrm{L}$ (normal range: 115-359 U/L) and 96 $\mathrm{U} / \mathrm{L}$ (normal range: 11-58 U/L), respectively. The level of the tumor marker elastase-1 was elevated to 1,600 ng/dL; however, carcinoembryonic antigen and carbohydrate antigen 19-9 (CA19-9) were in the normal ranges. An immunological examination revealed that the serum IgG and IgG4 levels were elevated to $1,936 \mathrm{mg} / \mathrm{dL}$ (normal range: $870-1,700 \mathrm{mg} / \mathrm{dL}$ ) and $307 \mathrm{mg} / \mathrm{dL}$ (normal range: 4.8-105 mg/dL), respectively. Contrast-enhanced CT showed two clear boundary mass lesions in the pancreatic head and tail, measuring 32 and $50 \mathrm{~mm}$ in diameter, respectively. The mass lesions exhibited low density in the early phase (Fig. 1a, b) and iso-density in the delayed phase. Magnetic resonance imaging (MRI) showed that the mass lesions exhibited low intensity on T1-weighted images (Fig. 1c, d) and iso-intensity on T2-weighted images. Magnetic resonance cholangiopancreatography showed an obstruction of the main pancreatic duct (MPD) in the pancreatic head and tail; however, the MPD in the pancreatic body was not dilated (Fig. 1e). The possibility of malignant tumors could not be ruled out because of a high level of serum elastase- 1 and atypical image findings of AIP; therefore, we performed total pancreatectomy. Cut surfaces of a resected specimen showed nodular lesions; however, the border between the lesions and the surrounding pancreatic parenchyma was unclear (Fig. 2a, b). A histopathological examination of the nodular lesions revealed severe lymphoplasmacytic infiltration and inflammatory change around the pancreatic ducts (Fig. 3a, b). Immunohistochemistry revealed diffuse infiltration of IgG4-positive plasma cells in the nodules (Fig. 3c, d). According to these pathological findings, we diag- 


\section{Case Reports in \\ Gastroenterology}

Case Rep Gastroenterol 2017;11:686-693

(c) 2017 The Author(s). Published by S. Karger AG, Base www.karger.com/crg

Suzumura et al.: Multifocal Mass Lesions in Autoimmune Pancreatitis

nosed the patient with IgG4-related AIP. However, it was difficult to control his erratic blood sugar level postoperatively, and he was discharged on the 72nd day after surgery. He has remained well for 78 months after undergoing surgery.

\section{Discussion}

Since Yoshida et al. [1] first proposed the term "autoimmune pancreatitis (AIP)" in 1995, this unique pancreatic disorder has been widely recognized as a new clinical entity. AIP is a type of rare chronic pancreatitis characterized by an autoimmune inflammatory process. The overall prevalence of this disease accounts for $2-10 \%$ of all patients with chronic pancreatitis. In 2002, the Japan Pancreas Society first established the "Diagnostic Criteria for Autoimmune Pancreatitis." Korea and the Mayo Clinic in the United States also subsequently established criteria. The integrated diagnostic criteria for AIP were established by the International Association of Pancreatology through an international consensus in 2010, featuring criteria for imaging, laboratory data, extrapancreatic organ involvement, histopathology, and treatment. The typical findings of AIP, such as diffuse swelling of the pancreas with stricture of the MPD, are useful for diagnosing AIP. However, AIP with focal mass lesion, which can mimic PC, remains difficult to differentiate from PC.

The image findings are essential for the diagnosis of both AIP and PC. Sun et al. [13] reported that radiological imaging features helpful for diagnosing focal mass lesion included (1) sausage-shaped enlargement, (2) delayed homogeneous enhancement, (3) hypoattenuating capsule-like rim, (4) irregular narrowing of the MPD and/or stricture of the common bile duct, and (5) MPD upstream dilatation $\leq 5 \mathrm{~mm}$. In the present, the possibility of PC could not be ruled out because such typical image findings were not observed.

In 2001, Hamano et al. [14] reported that patients with AIP have a high serum concentration of IgG4. Hirano et al. [15] also reported that serum IgG4 was elevated in the cases of focal AIP and that the serum IgG4 levels might be helpful for its diagnosis. However, careful consideration must be given if serum IgG4 is used as a specific indicator in the differential diagnosis between AIP and PC. This is because $>20 \%$ of all AIP patients have normal IgG4 levels, whereas $7-10 \%$ of PC patients have elevated IgG4 levels. Therefore, elevation of the serum IgG4 level alone is not sufficient for an AIP diagnosis. In the present case, we considered the possibility of multifocal AIP because of the high serum IgG4 levels.

Endoscopic ultrasound-guided fine needle aspiration (EUS-FNA) of the pancreas or EUS Trucut biopsy is useful for the differential diagnosis between AIP and PC. However, PC is difficult to exclude using biopsy specimens alone because of reactive inflammatory cell reactions and fibrosis surrounding the neoplastic cells. In the present case, EUS-FNA was unfortunately not performed for the diagnosis of pancreatic mass lesions.

The presence of multiple mass lesions in the pancreas is rare. There are a few reports of AIP with multifocal mass lesions. Only 9 cases of AIP with multiple mass lesions have been reported, including our case (Table 1) [6-12]. In these cases, the patient age ranged from 50 to 72 years (average: 61 years) and included 7 males and 2 females. The most frequent symptom was jaundice. Additionally, the patients tended to have high serum levels of IgG and/or IgG4. Only 2 patients avoided unnecessary surgery. 
Suzumura et al.: Multifocal Mass Lesions in Autoimmune Pancreatitis

\section{Conclusions}

It is important to recognize that AIP rarely exhibits multifocal mass lesions within the pancreas. It is still difficult to discriminate AIP from PC. However, if multiple mass lesions in the pancreas such as our case appear, then the serum IgG4 level should be evaluated and EUS-FNA performed for an accurate diagnosis to avoid unnecessary surgery.

\section{Statement of Ethics}

Approval from the Ethics Committee was not required for this case reports. Written informed consent was obtained from the patient for publication of this case report and any accompanying images.

\section{Disclosure Statement}

None of the authors has any financial conflicts of interest to declare.

\section{References}

1 Yoshida K, Toki F, Takeuchi T, Watanabe S, Shiratori K, Hayashi N: Chronic pancreatitis caused by an autoimmune abnormality. Proposal of the concept of autoimmune pancreatitis. Dig Dis Sci 1995;15611568.

2 Wakabayashi T, Kawaura Y, Satomura Y, Watanabe H, Motoo Y, Okai T, Sawabu N: Clinical and imaging features of autoimmune pancreatitis with focal pancreatic swelling or mass formation: comparison with so-called tumor-forming pancreatitis and pancreatic carcinoma. Am J Gastroenterol 2003;98:2679-2687.

-3 Kamisawa T, Egawa N, Nakajima H, Tsuruta K, Okamoto A, Kamata N: Clinical difficulties in the differentiation of autoimmune pancreatitis and pancreatic carcinoma. Am J Gastroenterol 2003;98:2694-2699.

4 Sahani DV, Kalva SP, Farrell J, Maher MM, Saini S, Mueller PR, Lauwers GY, Fernandez CD, Warshaw AL, Simeone JF: Autoimmune pancreatitis: imaging features. Radiology 2004;233:345-352.

-5 Matsubara T, Sakurai Y, Miura H, Kobayashi H, Shoji M, Nakamura Y, Imazu H, Hasegawa S, Ochiai M, Funabiki T: Complete obstruction of the lower common bile duct caused by autoimmune pancreatitis: is biliary reconstruction really necessary? J Hepatobiliary Pancreat Surg 2005;12:76-83.

6 Ohana M, Okazaki K, Hajiro K, Kobashi Y: Multiple pancreatic masses associated with autoimmunity. Am J Gastroenterol 1998;93:99-102.

7 Mikami K, Itoh H: MR imaging of multifocal autoimmune pancreatitis in the pancreatic head and tail: a case report. Magn Reson Med Sci 2002;1:54-58.

-8 Inoue D, Gabata T, Matsui O, Zen Y, Minato H: Autoimmune pancreatitis with multifocal mass lesions. Radiat Med 2006;24:587-591.

-9 Kajiwara M, Kojima M, Konishi M, Nakagohri T, Takahashi S, Gotohda N, Hasebe T, Ochiai A, Kinoshita T: Autoimmune pancreatitis with multifocal lesions. J Hepatobiliary Pancreat Surg 2008;15:449-452.

10 Shiokawa M, Kodama Y, Hiramatsu Y, Kurita A, Sawai Y, Uza N, Watanabe T, Chiba T: Autoimmune pancreatitis exhibiting multiple mass lesion. Case Rep Gastroenterol 2011;5:528-533.

11 Kimura A, Yamamoto J, Hatsuse K, Aosasa S, Nishiyama K, Maejima T, Ogata S, Shimazaki H, Kawaguchi A, Hase K: Multifocal lesions with pancreatic atrophy in IgG4-related autoimmune pancreatitis: report of a case. Surg Today 2014;44:1171-1176. 
Suzumura et al.: Multifocal Mass Lesions in Autoimmune Pancreatitis

Rotzinger R, Bläker H, Bahra M, Denecke T, Grieser C: CT and MRI findings of autoimmune polymorph bifocal pancreatitis mimicking pancreatic adenocarcinoma: a case report and review of the literature. J Investig Med High Impact Case Rep 2015;3:2324709615576988.

-13 Sun GF, Zuo CJ, Shao CW, Wang JH, Zhang J: Focal autoimmune pancreatitis: radiological characteristics help to distinguish from pancreatic cancer. World J Gastroenterol 2013;19:3634-3641.

14 Hamano H, Kawa S, Horiuchi A, Unno H, Furuya N, Akamatsu T, Fukushima M, Nikaido T, Nakayama K, Usuda N, Kiyosawa K: High serum IgG4 concentrations in patients with sclerosing pancreatitis. N Engl J Med 2001;344:732-738.

15 Hirano K, Komatsu Y, Yamamoto N, Nakai Y, Sasahira N, Toda N, Isayama H, Tada M, Kawabe T, Omata M: Pancreatic mass lesions associated with raised concentration of IgG4. Am J Gastroenterol 2004;99:2038-2040. 

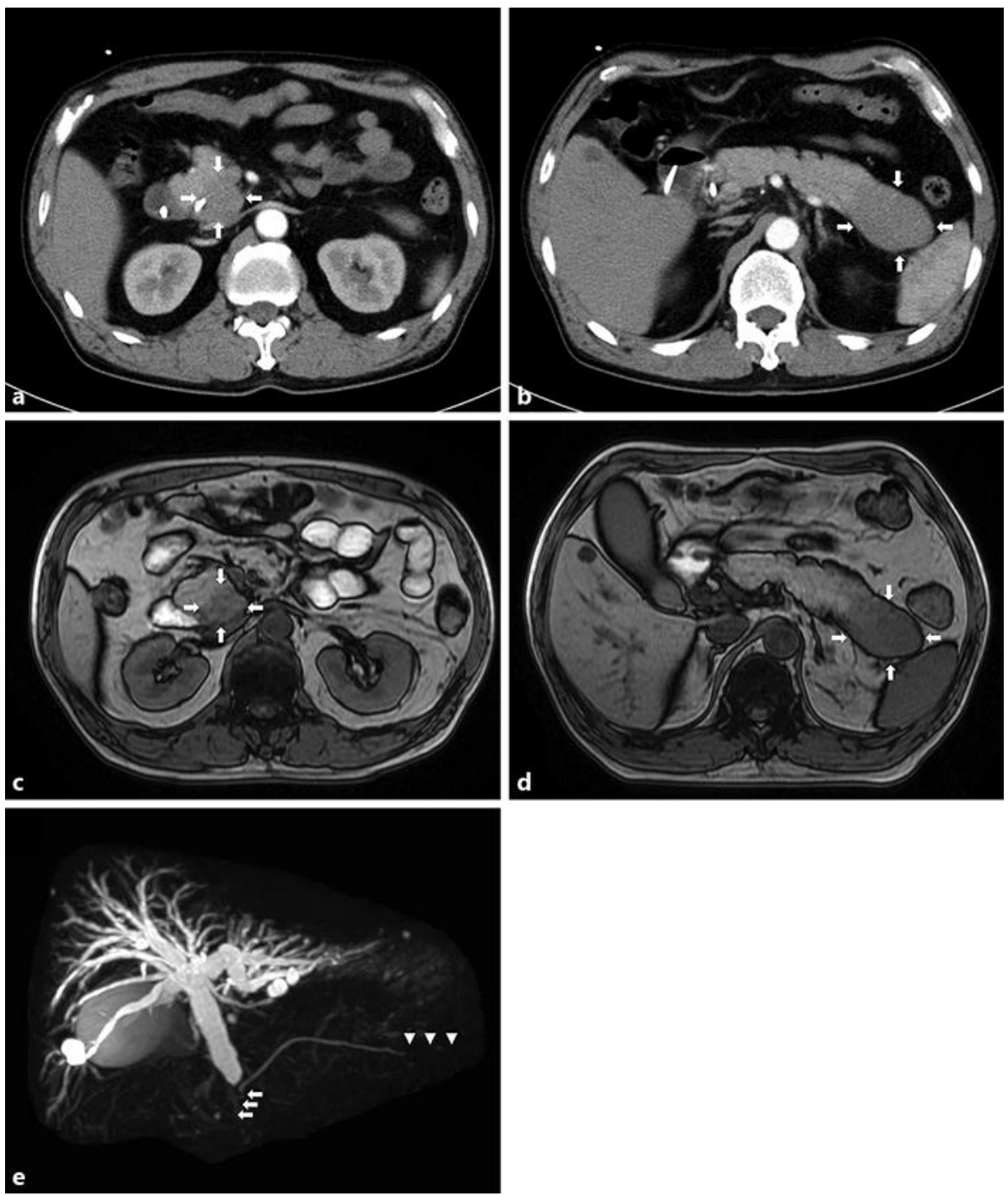

(c) 2017 The Author(s). Published by S. Karger AG, Basel www.karger.com/crg

Suzumura et al.: Multifocal Mass Lesions in Autoimmune Pancreatitis

Fig. 1. a Computed tomography (CT) showed a low-density mass lesion in the early phase and a clear boundary in the pancreatic head, measuring $32 \mathrm{~mm}$ in diameter (arrows). b CT showed a low-density mass lesion in the early phase and a clear boundary in the pancreatic tail, measuring $50 \mathrm{~mm}$ in diameter (arrows). c Magnetic resonance imaging (MRI) showed that the mass lesion in the pancreatic head exhibited low intensity on T1-weighted images (arrows). d MRI showed that the mass lesion in the pancreatic tail exhibited low intensity on T1-weighted images (arrows). e Magnetic resonance cholangiopancreatography (MRCP) showed an obstruction of the main pancreatic duct (MPD) in the pancreatic head (arrows) and tail (arrowheads); however, the MPD in the pancreatic body was not dilated. 


\section{Case Reports in Gastroenterology}

Case Rep Gastroenterol 2017;11:686-693
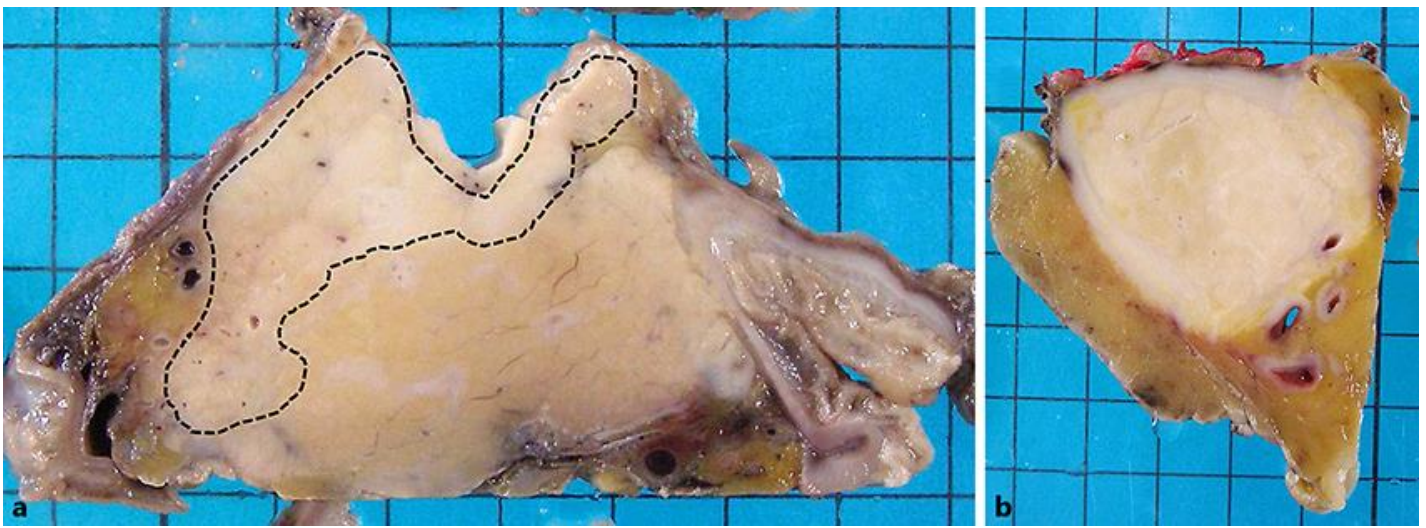

Fig. 2. a Cut surfaces of a resected specimen showed nodular lesions in the pancreatic head (dotted line); however, the border between the lesions and the surrounding pancreatic parenchyma was unclear. b Cut surfaces of a resected specimen showed nodular lesions in the pancreatic tail.

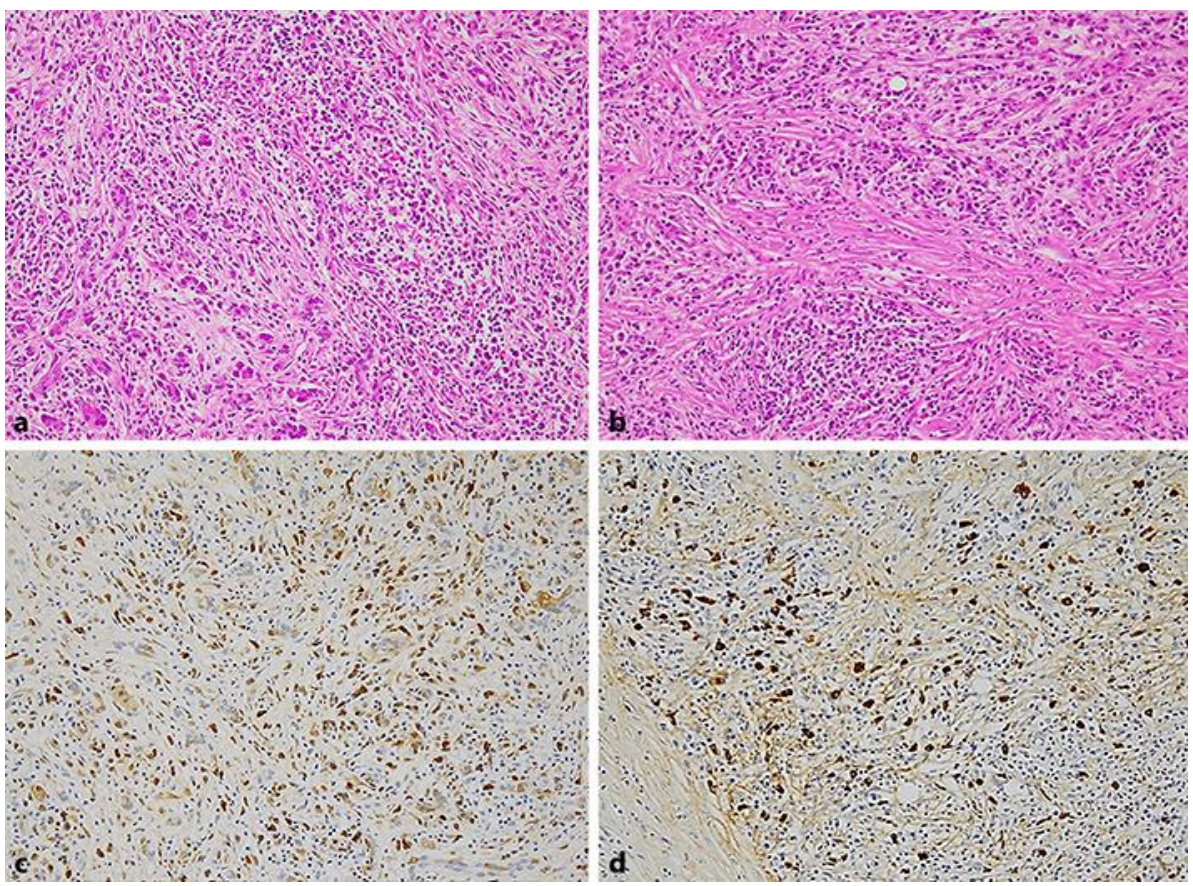

Fig. 3. Histopathological examination of the nodular lesions revealed severe lymphoplasmacytic infiltration and inflammatory change around the pancreatic ducts (a: head mass, b: tail mass) (hematoxylin and eosin staining $\times 200$ ). Immunohistochemistry revealed diffuse infiltration of IgG4-positive plasma cells in the nodules (c: head mass, d: tail mass) $(\times 200)$. 
Suzumura et al.: Multifocal Mass Lesions in Autoimmune Pancreatitis

Table 1. Reported cases of autoimmune pancreatitis with multifocal mass lesions

\begin{tabular}{|c|c|c|c|c|c|c|c|c|c|c|c|}
\hline Case & First author [Ref] & Year & $\begin{array}{l}\text { Age, } \\
\text { years }\end{array}$ & Gender & Symptoms & $\begin{array}{l}\text { Extrapancreatic } \\
\text { lesion }\end{array}$ & Location & IgG/IgG4 & $\begin{array}{l}\text { CEA/ } \\
\text { CA19-9 }\end{array}$ & Biopsy & $\begin{array}{l}\text { Final diagnosis } \\
\text { method }\end{array}$ \\
\hline 1 & Ohana [6] & 1998 & 59 & $\mathrm{~F}$ & Puffy face & Sjögren syndrome & $\mathrm{U}, \mathrm{B}, \mathrm{T}$ & $2,230 / \mathrm{ND}$ & NR/NR & + & $\begin{array}{l}\text { Operation } \\
\text { (wedged biopsy) }\end{array}$ \\
\hline 2 & Mikami [7] & 2002 & 50 & M & $\begin{array}{l}\text { Epigastralgia, } \\
\text { Jaundice }\end{array}$ & None & $\mathrm{H}, \mathrm{T}$ & $1,975 / \mathrm{ND}$ & $\mathrm{ND} / \mathrm{ND}$ & + & $\begin{array}{l}\text { US-guided percuta- } \\
\text { neous needle biopsy }\end{array}$ \\
\hline 3 & Inoue [8] & 2006 & 59 & M & Epigastralgia & None & $\mathrm{H}, \mathrm{U}, \mathrm{B}$ & NR/ND & $5.2 / \mathrm{NR}$ & - & Operation (PD) \\
\hline 4 & Kajiwara [9] & 2008 & 62 & M & Epigastralgia & ND & $\mathrm{H}, \mathrm{B}$ & ND/149 & NR/NR & + & Operation (PD) \\
\hline 5 & Kajiwara [9] & 2008 & 64 & M & None & ND & $\mathrm{B}, \mathrm{T}$ & ND/183 & ND/ND & - & Operation (DP) \\
\hline 6 & Shiokawa [10] & 2011 & 63 & M & None & $\begin{array}{l}\text { Bilateral swelling of } \\
\text { submandibular gland }\end{array}$ & H, B & $\mathrm{NR} / 773$ & NR/55.5 & + & EUS-FNA \\
\hline 7 & Kimura [11] & 2014 & 72 & M & Jaundice & None & $\mathrm{H}, \mathrm{B}, \mathrm{T}$ & $1,200 / 154$ & $<0.4 / 2.4$ & - & Operation (TP) \\
\hline 8 & Rotzinger [12] & 2015 & 58 & $\mathrm{~F}$ & $\begin{array}{l}\text { Back pain, jaundice, } \\
\text { weight loss }\end{array}$ & None & $\mathrm{H}, \mathrm{T}$ & ND/ND & $1.7 / 100$ & - & Operation (TP) \\
\hline 9 & Our case & 2017 & 59 & M & Jaundice & None & $\mathrm{H}, \mathrm{T}$ & $1,936 / 307$ & $1.3 / 18.8$ & - & Operation (TP) \\
\hline
\end{tabular}

ND, not described; NR, normal range; $\mathrm{H}$, head; U, uncus; B, body; T, tail; PD, pancreatoduodenectomy; DP, distal pancreatectomy; TP, total pancreatectomy. 